NBER WORKING PAPER SERIES

\title{
THE EFFECTS OF LAND MARKETS ON RESOURCE ALLOCATION AND AGRICULTURAL PRODUCTIVITY
}

\author{
Chaoran Chen \\ Diego Restuccia \\ Raül Santaeulàlia-Llopis \\ Working Paper 24034 \\ http://www.nber.org/papers/w24034
NATIONAL BUREAU OF ECONOMIC RESEARCH
1050 Massachusetts Avenue
Cambridge, MA 02138 \\ November 2017, Revised January 2021
}

\begin{abstract}
We thank Stephen Ayerst, Loren Brandt, Rui Castro, Murat Celik, Leandro De Magalhães, Margarida Duarte, Doug Gollin, Andre Groger, Joan Llull, Hannes Mueller, Amma Panin, Xiaodong Zhu, and seminar participants at Fudan University, McMaster University, Midwest Macro Conference at Louisiana State University, National University of Singapore, Shanghai University of Finance and Economics, Singapore Management University, Syracuse University, University of Lausanne, University of Oxford, and the World Bank for useful comments. All remaining errors are our own. Chen thanks the National University of Singapore for the faculty start-up grant (R122000266133) while he worked on this paper and the financial support from York University and the Social Sciences and Humanities Research Council of Canada. Restuccia gratefully acknowledges the financial support from the Canadian Research Chairs program and the Social Sciences and Humanities Research Council of Canada. Raül Santaeulàlia-Llopis thanks the ERC AdG-GA324048, "Asset Prices and Macro Policy when Agents Learn (APMPAL)", ERC Grant 788547 (APMPAM-HET) and the Spanish Ministry of Economy and Competitiveness through the Proyectos I+D+i 2019 Retos Investigacion PID2019-110684RB-I00 Grant and the Severo Ochoa Programme for Centers of Excellence in R\&D (SEV-2015-0563) for financial support. The views expressed herein are those of the authors and do not necessarily represent those of the National Bureau of Economic Research.
\end{abstract}

NBER working papers are circulated for discussion and comment purposes. They have not been peer-reviewed or been subject to the review by the NBER Board of Directors that accompanies official NBER publications.

(C) 2017 by Chaoran Chen, Diego Restuccia, and Raül Santaeulàlia-Llopis. All rights reserved. Short sections of text, not to exceed two paragraphs, may be quoted without explicit permission provided that full credit, including $(\mathrm{C}$ notice, is given to the source. 
The Effects of Land Markets on Resource Allocation and Agricultural Productivity

Chaoran Chen, Diego Restuccia, and Raül Santaeulàlia-Llopis

NBER Working Paper No. 24034

November 2017, Revised January 2021

JEL No. E02,O11,O13,O55,Q1

\begin{abstract}
We assess the effects of land markets on misallocation and productivity both empirically and quantitatively. Exploiting variation from a land certification reform across time and space in Ethiopia, we find that certification facilitates rentals and improves agricultural productivity. We calibrate a quantitative macroeconomic model with heterogeneous household farms facing institutional costs to land markets using the micro panel data. The effect of a counterfactual reallocation from no rentals to efficient rentals increases zone-level agricultural productivity by 43 percent on average. While our estimated institutional costs are strongly associated with land certification across zones, there are nontrivial residual frictions to rental market activity, implying that land certification only partially captures the overall effects of rentals. A full certification reform accounts for just one-fourth of the overall productivity gains from land rentals. This result highlights the importance of comprehensive reforms alleviating frictions to land transactions beyond the granting of certificates.

Chaoran Chen

York University

4700 Keele St.

Toronto, ON M3J 1P3

Canada

chenecon@yorku.ca

Diego Restuccia

Department of Economics

University of Toronto

150 St. George Street

Toronto, ON M5S 3G7

CANADA

and NBER

diego.restuccia@utoronto.ca

\author{
Raül Santaeulàlia-Llopis \\ MOVE, UAB, and Barcelona GSE \\ Plaza Civica s/n \\ Bellaterra, Barcelona \\ 08193 \\ Spain \\ rauls@movebarcelona.eu
}




\section{Introduction}

What are the effects of land markets on resource allocation and agricultural productivity? Despite the importance and large efforts devoted into understanding land markets, the answer to whether land markets improve resource allocation and productivity remains elusive (Deininger and Feder, 2001). We study the effects of land rental markets on agricultural productivity using evidence from a land certification reform in Ethiopia together with a quantitative macroeconomic model that captures institutional costs beyond access to land certification. We show that rentals significantly improve agricultural productivity by reducing misallocation and that the empirical effects of a land certification reform only capture a fraction of the overall effects of land markets.

Ethiopia provides a unique and relevant context to investigate the effects of land markets on productivity. From 1974 until the early-1990s, the Communist government in power expropriated and uniformly redistributed all of the rural land in the country, and prohibited land transactions by law. Although land ownership still resides with the state, an ongoing land certification reform allows land to be reallocated across farmers via rentals up to a limit and with restrictions (Holden and Ghebru, 2016). The land certification reform, and hence the lifting of barriers to land rental market activity, was decentralized and implemented by local governments with different intensity and timing across zones (i.e., sub-regions) as opposed to being contemporaneously implemented by the central government (Deininger

et al., 2008), providing an interesting source of variation. Using representative panel data that catches the reform in the 2010s, in two waves 2013/14 and 2015/2016, we find large variation in the fraction of land parcels with a certificate (land certification share) and rental 
market activity across space and time.

We provide microeconomic empirical evidence that increases in land rental market activity improves resource allocation by comparing zones that do and do not increase land rentals. Since rentals are an endogenous outcome of changes in institutional costs, we explicitly exploit the variation in land certification shares across space and time in order to infer the empirical effects of land certificates on rentals and misallocation. Using a differencein-difference strategy we compare zones (treatment group) for which certification shares increase between the 2013/14 and the 2015/16 waves with zones (control group) for which certification shares do not increase. We find that land certification significantly facilitates land rentals and improves resource allocation. We assess the exogeneity of the certification reform by showing no pre-trend differences and through a placebo test.

We emphasize that the empirical effects of the land certification reform may not reflect the entire scope of how land markets alleviate misallocation and improve productivity. For instance, there may be a lagging behavior between the granting of land certificates and farms' engagement in land rental activity due to the potential lack of trust in the institutional reform (Ostrom, 2010). It could also be that there are other frictions impeding the efficient allocation of land through rentals, in addition to lacking certificates. To assess the broader effects of land markets on resource allocation, we develop a quantitative model with endogenous rentals, where household-farms are heterogeneous in their permanent productivity and face zone-specific land-market institutional costs. We calibrate our baseline economy, including zone-specific institutional costs and the joint distribution of productivity and land endowments, to the 2013/14 wave of data and refer to this allocation as status quo.

We conduct two main quantitative experiments. First, we vary the land-market in- 
stitutional costs to match the 2015/16 moments of land rentals and refer to the implied allocations as reform. We then estimate the relationship between rentals and productivity using the model-generated status quo and reform allocations and find that the differencein-difference estimates are very similar to those obtained from the empirical data. While the calibrated institutional costs encompass all frictions to land markets, they are highly correlated with the land certification shares across zones, providing further evidence that the certification reform helps facilitate rentals. We also find that the history of reform matters since zones in which certificates are granted earlier experience a more rapid decline in institutional costs, suggesting a lag between the granting of certificates and land reallocation. Second, using the empirical relationship between land certification and institutional costs, we vary land certification shares in each zone from zero to 100 percent and find that this counterfactual full certification reform increases zone-level agricultural productivity by 10.8 percent on average. We contrast this result with an alternative counterfactual obtained by varying institutional costs in each zone from prohibitively high to zero, which captures changes in allocations from no rentals to efficient rentals. The overall effect of rentals is an increase of zone-level agricultural productivity of 43.3 percent on average. We conclude that land certification only partially captures the effects from land markets, accounting for just about one-fourth of the overall effects from rentals.

A critical aspect of the political discourse on land policy in poor countries is whether land rentals enhance or reduce farm income inequality (Deininger and Binswanger, 1999; André and Platteau, 1998; Otsuka, 2007). A complete assessment of the effects of land rental markets on inequality is challenging as it requires data that is typically not available. We use our model-generated status quo and reform allocations to construct measures of 
within-zone farm-income inequality. We find that land certification does not increase zonelevel inequality, instead the increase in average farm income is particularly stronger for poor households.

Our paper relates to a macroeconomic literature on agricultural productivity and international income differences. ${ }^{1}$ The measurement of the extent of misallocation in poor countries has been emphasized using micro panel data (Restuccia and Santaeulàlia-Llopis, 2017; Gollin and Udry, 2017). We focus on the changes in misallocation due to the effects of land markets as opposed to the level of misallocation. We have identified underdeveloped land markets as one source of factor misallocation (Restuccia and Rogerson, 2017), relating to the role of institutions on development (Acemoglu et al., 2001; Banerjee et al., 2002; Banerjee and Iyer, 2005). Land reforms have been studied extensively and, in particular, land certification policies have been addressed empirically. ${ }^{2}$ We contribute to this literature not only by providing evidence of land certification on rentals and productivity, but also by assessing how much land certification reform accounts for the overall effects of land rentals using theory that is consistent with the empirical effects. Our results show that focusing on the empirical causal effects of a specific land policy can substantially underestimate the overall effects of land markets. We also contribute to a growing literature that integrates micro empirical evidence with quantitative theory to assess macro development. ${ }^{3}$

In Section 2, we describe the data, the institutional background, and the land market

\footnotetext{
${ }^{1}$ See, for example, Gollin et al. (2002, 2004, 2007), Restuccia et al. (2008), Adamopoulos (2011), Lagakos and Waugh (2013), Adamopoulos and Restuccia (2014), Gollin et al. (2014), Chen (2017), Adamopoulos et al. (2017), Chen (2020), and Donovan (2020).

${ }^{2}$ See, for instance, Besley and Burgess (2000), Banerjee and Iyer (2005), Giné (2005) and Deininger et al. (2008). Land certification has been empirically addressed, for instance, in Deininger (2003) and de Janvry et al. (2015), and also more recently in a contemporaneous paper by Chari et al. (2020).

${ }^{3}$ See, for instance, Mobarak and Rosenzweig (2014), Bryan et al. (2014), Lagakos et al. (2018), Meghir et al. (2019), De Magalhães et al. (2019), and Brooks et al. (2020).
} 
activity in Ethiopia. Section 3 presents the theoretical framework and the qualitative effects of land markets. In Section 4, we discuss the empirical evidence of the effects of land certification reform. Section 5 quantifies the effects of land markets on resource allocation and productivity, contrasting the effects of land certification with the overall effects of land rentals. In Section 6, we study the inequality implications of land reform. Section 7 concludes.

\section{Data and Institutional Background}

Data. We use household-level panel data from the World Bank, the Ethiopia Integrated Survey of Agriculture (ISA), for waves 2013/14 and 2015/16. The ISA's provide information over the entire process of crop production, including physical measures of farm inputs and outputs. These are representative surveys of the population, with approximately 5,250 households interviewed per wave of which two thirds live in rural areas and work in agricultural production. Households are surveyed twice in a year: the first round occurs during the planting season, and the second round during the harvest season.

Almost all farms in Ethiopia are family farms. Therefore, we treat a family farm operated by a household as our basic unit of production. We construct our measures of factor inputs, outputs, and total factor productivity (TFP) at the household-farm level. A household-farm typically consists of several plots of land; we therefore aggregate the inputs and outputs of these plots to the household level. We describe in detail our variables of output, capital, land quality, land, and labor input, as well as transitory shocks such as rain, in Appendix A.

The panel dimension of the Ethiopia ISA data is key in two aspects of our analysis. 
First, we use the panel dimension of the survey data to compute a permanent component of household farm TFP. This permanent component-or fixed effect-captures unobserved heterogeneity in productivity. We use this benchmark productivity to conduct our reallocation exercises. Second, we use the variation in land market activity, both land certification and rentals, across time and space in Ethiopia to provide empirical evidence of the relationship between land certification, rentals, and agricultural productivity with an empirical strategy that requires the household-farm panel structure.

Institutional Background. Current land institutions in Ethiopia are shaped by historical events, but their prevailing characteristic has been state control over the allocation and use of land. The evolution of land institutions can be divided into three periods. The first period is the imperial period, spanning from the mid nineteenth century to 1974. During this period, land ownership was usually granted to political supporters regardless of occupation or use in farming, which created a feudal regime. Further emergence of private property during this period resulted in powerful landlords. The second period, from 1975 to 1991, resulted from the severe social injustices created by the feudal regime that lead to a Communist regime. A comprehensive land reform, "Land to the Tiller", was then implemented. The Communist government expropriated all of the land in the country and redistributed it to all rural households - adjusting for soil quality and family size - in the form of use rights. Land redistributions were frequent, every one to two years, to achieve an equitable allocation of use rights among the local rural populations, and land transactions were strictly prohibited.

The third period started with the collapse of the Communist regime in 1991, under a market-oriented government that has largely maintained land-related policies from the previous regime. Essentially, land ownership still resides with the state and households are 
assigned use rights by local authorities at the village (kebele) or district (woreda) level. Many of the restrictions to land transactions remain in place. However, land certification reforms have been implemented since the early 2000s to mainly promote tenure security by issuing land certificates of use rights. Farmers with these land certificates are allowed to rent out land with varied restrictions, but not to sell land because land is entirely owned by the state.

Land certification and rental market activity across space and time. We observe land certificates (if any) for each parcel of land. We measure the land certification share, $C_{z, t}$, as the ratio between the number of parcels with certificates and the total number of land parcels in a given zone (county) $z$ and time $t .{ }^{4}$ The statistics are reported in Table 1 . Two facts emerge: Overall more land parcels are certified over time as the implementation of the land reform progresses, while the certification share varies substantially across zonessome zones have not started certification while others have almost all land parcels certified. The heterogeneity should not be completely surprising given that the reform is implemented by local authorities. Across time between the 2013/14 and 2015/16 waves, 36 out of 69 zones feature an increase in the land certification share. We also measure land rental market activity, $R_{z, t}$, as the ratio between the size of total rented land and the size of total cultivated land in a given zone $z$ and period $t$, and report statistics in Table 1. Despite the land reform, the land rental market is relatively under-developed in Ethiopia and land rentals increase less than land certificates. This is in part because severe restrictions on land rentals remain in place, for example, only a fraction of use rights can be rented and the renting household must dwell in the rural area as well as be engaged only in farming (Holden and Ghebru,

\footnotetext{
${ }^{4}$ There are four levels of administrative divisions in Ethiopia: regions (states), zones (counties), woreda (districts), and kebele (wards). Due to sample size, we focus our analysis at the zone level that have a relatively large number of observations for each zone.
} 
Table 1: Land Certification and Rentals across Time and Space (Zones)

(a) The Share of Land Parcels with Certificates

\begin{tabular}{cccccccc}
\hline & Aggregate & 10 pct & 25 pct & Median & 90 pct & Max. & $\#$ \\
$C_{z, 2013 / 14}$ & 36.3 & 0.0 & 4.0 & 29.7 & 78.9 & 92.5 & 69 \\
$C_{z, 2015 / 16}$ & 41.7 & 0.0 & 17.5 & 45.2 & 76.0 & 95.7 & 69 \\
\hline \multicolumn{7}{c}{ (b) The Share of Land Rentals } \\
\hline \multicolumn{7}{c}{ Percent } \\
$R_{z, 2013 / 14}$ & 11.0 & 0.0 & 1.8 & 5.8 & 24.7 & 71.7 & 69 \\
$R_{z, 2015 / 16}$ & 11.3 & 0.0 & 1.4 & 8.1 & 25.9 & 76.5 & 69 \\
\hline
\end{tabular}

Notes: Data from Ethiopia ISA 2013/14 and 2015/16 waves. The land certification share $C_{z}$ is the ratio between the number of parcels with certificates and the total number of land parcels in a given zone $z$ and time $t$. The share of land rentals $R_{z}$ is the ratio between total operated rented land and total cultivated land. Distributional statistics of $C_{z}$ and $R_{z}$ separately for each wave.

2016). We also find substantial variation in land rentals across space and time.

The fact that the lifting of barriers to land rental market activity was implemented by local governments with different intensity and timing across zones (i.e., sub-regions) is likely to contribute to the current landscape of land market activity across space and time in Ethiopia. This is however hard to determine. For example, the granting of land certificates does not necessarily generate immediate land market activity, which is our object of interest. Indeed, we find that in 2013/14 there are 5 zones with granted land certificates where we do not observe land rental market activity at all. We find that the certificates in these zones were (on average) granted in 2005. That is, we find zones in which farms do not engage in land rentals in the 2010s even though land certificates were granted in those zones in the 2000s. This suggests that certain lagging behavior between the granting of land certificates and land rental activity exists. That is, it is plausible that it takes time for farmerswho throughout their lifetime have been subject to recurrent land expropriations by the 
government in Ethiopia - to trust and use the new land rental entitlements. Indeed, during the launching of the land reform, local governments still illegally evicted landholders with de-facto imprisonment threats (ELTAP, 2007), which further depletes trust (Ostrom, 2010). For this reason, our analysis focuses on land rentals and land certification separately, and aims to quantify the productivity gains arising from land certification reform and contrast them to the overall efficiency gains from land rentals. Nevertheless, land rentals are clearly associated with the land certification reform since the zone-level Spearman's rank correlation are 0.34 and 0.41 for the $2013 / 14$ and $2015 / 16$ waves, both significant at the one percent level.

\section{A Theoretical Framework}

We develop a quantitative macroeconomic model to assess the effects of land rental markets on resource misallocation and productivity in Ethiopia. We narrowly focus on zone-level reallocations and, as a result, when clear we abstract from the zone-level index $z$.

\section{$3.1 \quad$ Setup}

Production. Our economy is populated by heterogeneous household farms indexed by $i$ that differ in their permanent productivity, $s_{i} \in\{1, \ldots, S\}$. Each farm produces a homogeneous agricultural good using the following decreasing returns to scale technology:

$$
\widetilde{y}_{i t}=\left(s_{i} \zeta_{i t}\right)^{1-\gamma}\left(k_{i t}^{\alpha} \ell_{i t}^{1-\alpha}\right)^{\gamma},
$$

where $\widetilde{y}_{i t}$ is the output of farm $i$ in period $t$ (measured as value added net of intermediates such as fertilizer and seeds), $k_{i t}$ is the capital input and $\ell_{i t}=q_{i t} l_{i t}$ is quality adjusted land 
input, where $q_{i t}$ is land quality and $l_{i t}$ is land size.

Notice that household-farm productivity consists of a permanent component, $s_{i}$, that does not change over time and a transitory component $\zeta_{i t}$ (e.g., rain shocks and illnesses). All variables are in per capita (hourly) terms following the idea that the reallocations of capital and land that we conduct across household farms are not accompanied by the reallocation of household members across farms since agricultural production is largely provided within family. Nevertheless, we conduct robustness to this assumption in the appendix.

Two remarks are in order. First, we are interested in reallocations guided only by the permanent component of productivity $s_{i}$. For this reason, we use our panel data to recover this permanent fixed-effect component and measure the transitory shocks $\zeta_{i t}$ as residual deviations from the permanent component. Second, we also use our rich data on land quality at the plot level to net its effects on output. As a result, we define our benchmark output $y_{i t}$ as output net of transitory shocks and land quality,

$$
y_{i t}=\frac{\widetilde{y}_{i t}}{\zeta_{i t}^{1-\gamma} q_{i t}^{(1-\alpha) \gamma}}=s_{i}^{1-\gamma}\left(k_{i t}^{\alpha} l_{i t}^{1-\alpha}\right)^{\gamma}
$$

where $\gamma \in(0,1)$ governs returns to scale at the farm level and $\alpha$ is a factor share parameter.

Measuring farm productivity. We use the micro data to estimate factor income shares to pin down the values for $\alpha$ and $\gamma$ and use these parameters to measure farm productivity. We find that the capital, labor, and land shares are $0.147,0.464$, and 0.389 , respectively. This implies that $\alpha=0.274$ and $\gamma=0.536$. (Appendix B provides details and a discussion of robustness to alternative values.) Given values for $\alpha$ and $\gamma$, together with farms' actual inputs (including land quality) and outputs in the data, we recover farm-level productivity separately for each year, $s_{i} \zeta_{i t}$, which is the product of a permanent $s_{i}$ and transitory component 
$\zeta_{i t}$. We then use the panel data to recover our benchmark measure of permanent farm-level productivity $s_{i}$, which is constructed as the geometric mean of farm-level productivity across years. That is, our benchmark productivity measure $s_{i}$ is equivalent to the outcome of an estimation of household-farm fixed effects of productivity (in logs) and, hence, it captures permanent unobserved heterogeneity across farms. After observing the implied distribution of productivity we trim approximately one percent of the farm productivity distribution to remove candidate outliers which may reflect measurement error in inputs and outputs. Notice that although farm productivity $s_{i}$ is invariant to time, farm output and factor inputs can change over time, see equation (1). However, for the ease of notation, in what follows, we drop time subscripts for all variables in our analysis.

Farm problem. Extending the production framework, we assume that each household farm is endowed with $\bar{l}$ units of land and can rent capital and land taking costs as given. Farms choose their operational scale solving the following profit maximization problem:

$$
\max _{k_{i}, l_{i}} \pi\left(s_{i}, \bar{l}_{i}\right)=s_{i}^{1-\gamma}\left(k_{i}^{\alpha} l_{i}^{1-\alpha}\right)^{\gamma}-r k_{i}-c\left(l_{i}, \bar{l}_{i}\right),
$$

where $l_{i}$ and $\bar{l}_{i}$ denote the land operational scale and endowment. The function $c\left(l_{i}, \bar{l}_{i}\right)$ represents the cost of changing the amount of land operated relative to the endowment. This cost combines the rental cost of land with a land transaction cost that captures the institutional barriers to land rental markets determined by, for example, the amount of land certificates distributed in given zone that allow for rentals. We parameterize this cost as:

$$
c\left(l_{i}, \bar{l}_{i} ; \chi_{z}^{q}, \chi_{z}^{f}\right)=\left\{\begin{array}{l}
q\left(l_{i}-\bar{l}_{i}\right)+\frac{\chi_{z}^{q}}{2}\left(l_{i}-\bar{l}_{i}\right)^{2}+\chi_{z}^{f}, \quad \text { if } l_{i} \neq \bar{l}_{i}, \\
0, \quad \text { if } l_{i}=\bar{l}_{i}
\end{array}\right.
$$

where $q$ is the land rental rate, $q\left(l_{i}-\bar{l}_{i}\right)$ the land rental payment or receipt, $\chi_{z}^{q} / 2 \cdot\left(l_{i}-\bar{l}_{i}\right)^{2}$ is a 
quadratic adjustment cost, and $\chi_{z}^{f}$ is a fixed cost of participating in the land rental market. The quadratic and fixed costs parameters, $\left(\chi_{z}^{q}, \chi_{z}^{f}\right)$, represent the broad institutional barriers to land rental markets.

Equilibrium. Denote the optimal farm inputs from the profit maximization problem (2) as $l^{*}\left(s_{i}, \bar{l}_{i}\right)$ and $k^{*}\left(s_{i}, \bar{l}_{i}\right)$. Given a set of productivity and land endowments $\left(s_{i}, \bar{l}_{i}\right)$ among $S$ farmers in a zone and the zone-level amount of capital $K$, an equilibrium is a set of allocations $\left(l_{i}^{*}, k_{i}^{*}\right)$ and prices $(q, r)$ such that: $(i)$ Given prices $(q, r)$, farm allocations $\left(l_{i}^{*}, k_{i}^{*}\right)$ solve problem (2) and (ii) land and capital rental markets clear, that is, $\sum_{i} l^{*}\left(s_{i}, \bar{l}_{i}\right)=L=\sum_{i} \bar{l}_{i}$. and $\sum_{i} k^{*}\left(s_{i}, \bar{l}_{i}\right)=K$.

\subsection{Theoretical Effects of Land Rental Markets}

We use our theoretical framework to qualitatively examine the effects of frictions to land rental markets in order to guide the empirical and quantitative analyses. We separately solve for equilibrium allocations within zones.

We define the total amount of rentals (share of rented land) in a given zone as

$$
R_{z}=\frac{\sum_{i}\left(l^{*}\left(s_{i}, \bar{l}_{i}\right)-\bar{l}_{i}\right) \mathbb{1}\left(l^{*}\left(s_{i}, \bar{l}_{i}\right)>\bar{l}_{i}\right)}{\sum_{i} \bar{l}_{i}}
$$

where $\mathbb{1}\left(l^{*}\left(s_{i}, \bar{l}_{i}\right)\right)$ is a binary variable which is equal to one if farmer $i$ rents in land and zero otherwise. We use this binary variable to prevent double counting rented land.

Efficient allocation. We start by characterizing the efficient allocation in each zone, that is the allocations that maximize agricultural output subject to resource constraints, achieved in equilibrium when $\chi_{z}^{q}=0$ and $\chi_{z}^{f}=0$. It is straightforward to show in this case that the 
equilibrium allocations are, after solving for the equilibrium prices, given by

$$
l^{*}\left(s_{i}, \bar{l} ; \chi_{z}^{q, f}=0\right)=l^{e}\left(s_{i}\right)=\frac{s_{i}}{S_{z}} L_{z}
$$

where $S_{z}=\sum_{i} s_{i}$. That is, operated land is proportional to farmer's productivity $s_{i}$. The solution for capital is analogous. Notice that in this case the initial endowment $\bar{l}_{i}$ does not affect land operational scale, which is solely a function of individual productivity $s_{i}$. Clearly, land rentals are positive $\left(R_{z}>0\right)$ if the land endowment $\bar{l}_{i}$ differs from the efficient allocation $l_{i}^{e}\left(s_{i}\right)$ for some $i$. Farm output associated with the efficient allocation is

$$
y^{e}\left(s_{i}\right)=s_{i}^{1-\gamma}\left(k_{i}^{e}\left(s_{i}\right)^{\alpha} l_{i}^{e}\left(s_{i}\right)^{1-\alpha}\right)^{\gamma}=s_{i}\left(\frac{K_{z}^{\alpha} L_{z}^{1-\alpha}}{S_{z}}\right)^{\gamma} .
$$

The zone-level agricultural output associated with the efficient allocation is

$$
Y_{z}^{e}=\sum_{i \in z} y_{i}^{e}=S_{z}^{1-\gamma}\left(K_{z}^{\alpha} L_{z}^{1-\alpha}\right)^{\gamma}
$$

Allocations with imperfect land markets. When the institutional costs are positive, $\chi_{z}^{q}>0$ or $\chi_{z}^{f}>0$, the optimal farm operational land, if a farmer pays the fixed cost and participates in the land market, is the solution to following equation which results from using the first order conditions from problem (2),

$$
l_{i}^{*}=s_{i} \gamma^{\frac{1}{1-\gamma}}\left(\frac{\alpha}{r}\right)^{\frac{\alpha \gamma}{1-\gamma}}\left(\frac{1-\alpha}{q\left(1+\tau\left(l_{i}^{*}, \bar{l}_{i}\right)\right)}\right)^{\frac{1-\alpha \gamma}{1-\gamma}}
$$

where $\tau(l, \bar{l})=\chi_{z}^{q}(l-\bar{l}) / q$ represents an endogenous idiosyncratic land wedge (i.e., an implicit "distortionary tax" on the rental price of land). Since this wedge is increasing in $l_{i}^{*}$, there is a unique solution to this equation. The farmer could also choose not to pay the fixed cost by operating on his endowment only, in which case we have $l_{i}^{*}=\bar{l}_{i}$. This choice is based on 
comparing the profit with rentals net the fixed cost versus the profit operating on endowed land only. Clearly, the operational scale depends on $s_{i}$ and $\bar{l}_{i}$, hence we denote the solution as $l_{i}^{*}\left(s_{i}, \bar{l}_{i}\right)$. We can similarly solve for the capital input which is also indirectly affected by the land wedge.

Absent institutional $\operatorname{costs}\left(\chi_{z}^{q}=0\right.$ and $\left.\chi_{z}^{f}=0\right)$, land rentals are generally positive $\left(R_{z}>0\right)$. If institutional costs are prohibitively high $\left(\chi_{z}^{q} \rightarrow \infty\right.$ or $\left.\chi_{z}^{f} \rightarrow \infty\right)$, then the operational land of each farm is simply given by the land endowment,

$$
l_{i}^{*}\left(s_{i}, \bar{l}_{i}: \chi_{z}^{q} \rightarrow \infty \text { or } \chi_{z}^{f} \rightarrow \infty\right)=\bar{l}_{i}
$$

and rental markets collapse $\left(R_{z}=0\right)$. In the intermediate cases, land rentals $R_{z}$ decrease with $\chi_{z}^{q}$ and $\chi_{z}^{f}$. Provided land endowments are not efficient, then the amount of land rentals $R_{z}$ indicates the extent of institutional $\operatorname{costs}\left(\chi_{z}^{q}, \chi_{z}^{f}\right)$.

Measures of misallocation. Equilibrium farm output is given by $y_{i}^{*}=s_{i}^{1-\gamma}\left[\left(k_{i}^{*}\right)^{\alpha}\left(l_{i}^{*}\right)^{1-\alpha}\right]^{\gamma}$. As long as $\chi_{z}^{q}>0$ or $\chi_{z}^{f}>0$, farm output $y_{i}^{*}\left(s_{i}, \bar{l}_{i}\right)$ is generally different from the efficient output $y^{e}\left(s_{i}\right)$. Aggregate equilibrium output in a zone is then generally less than aggregate efficient output in a zone,

$$
Y_{z}^{*}=\sum_{i \in z} y_{i}^{*}\left(s_{i}, \bar{l}_{i}\right) \leqslant \sum_{i \in z} y^{e}\left(s_{i}\right)=Y_{z}^{e}
$$

The ratio of efficient to equilibrium output represents the efficiency gain of relocating resources in a zone,

$$
e_{z}=\frac{Y_{z}^{e}}{Y_{z}^{*}} \geqslant 1
$$

and is a measure of misallocation, with $e_{z}=1$ when $\chi_{z}^{q}=0$ and $\chi_{z}^{f}=0$. Intuitively, a positive $\chi_{z}^{q}$ or $\chi_{z}^{f}$ reduces equilibrium land rentals $R_{z}$ and hence prevents land from being 
allocated efficiently. As a result, $e_{z}$ decreases with equilibrium rentals $R_{z}$.

An alternative direct measure of the extent of misallocation is the dispersion in the marginal product of land among farmers within a zone. To see this, notice that if $\chi_{z}^{q}=0$ and $\chi_{z}^{f}=0$, then our economy attains the efficient allocations by equalizing the marginal product of land across all farms in zone $z$. The efficient marginal product of land for each farm $i$ is

$$
\operatorname{MPLa}_{i}^{*}\left(\chi_{z}^{q, f}=0\right)=\operatorname{MPLa}_{i}^{e}=(1-\alpha) \gamma \frac{y^{e}\left(s_{i}\right)}{l^{e}\left(s_{i}\right)}=(1-\alpha) \gamma \frac{Y_{z}^{e}}{L_{z}}
$$

which is identical across farmers. This implies that the within-zone dispersion (standard deviation) of the $\mathrm{MPLa}_{i}$ across farms is zero in the efficient allocation within a zone, and strictly positive when $\chi_{z}^{q}>0$ or $\chi_{z}^{f}>0$. Hence, we use dispersion in the marginal product of land as a measure of the extent of misallocation. Note that since institutional costs affect equilibrium land rentals, they imply a negative relationship between equilibrium land rentals $R_{z}$ and dispersion in the marginal product of land in a zone.

Another widely-used summary measure of misallocation as the dispersion of farm-level revenue productivity ("TFPR"). Under the efficient allocations in our framework, TFPR is given by

$$
\operatorname{TFPR}_{i}^{*}\left(\chi_{z}^{q, f}=0\right)=\operatorname{TFPR}_{i}^{e}=\frac{y_{i}^{e}\left(s_{i}\right)}{\left(k_{i}^{e}\left(s_{i}\right)\right)^{\alpha}\left(l_{i}^{e}\left(s_{i}\right)\right)^{1-\alpha}}=\frac{Y_{z}^{e}}{\left(K_{z}^{e}\right)^{\alpha}\left(L_{z}^{e}\right)^{1-\alpha}}
$$

which is a constant and hence also equalized across farms. Therefore, we also consider the dispersion (standard deviation) of TFPR across farms within a given zone as a measure the extent of misallocation (Hsieh and Klenow, 2009; Adamopoulos et al., 2017). Similarly, higher institutional costs reduce equilibrium rentals $R_{z}$ and increase the dispersion of TFPR. 
We also construct corresponding farm-level measures of misallocation to facilitate our empirical analysis. We define the farm-level efficiency gain as the ratio of efficient to equilibrium output, $e_{i}=y_{i}^{e}\left(s_{i}\right) / y_{i}^{*}\left(s_{i}, \bar{l}_{i}\right)$, which is equal to one when there is no misallocation. Similarly, we define the farm-level MPLa and TFPR as

$$
\operatorname{MPLa}_{i}=\frac{y_{i}^{*}\left(s_{i}, \bar{l}_{i}\right)}{l_{i}^{*}\left(s_{i}, \bar{l}_{i}\right)}, \quad \operatorname{TFPR}_{i}=\frac{y_{i}^{*}\left(s_{i}, \bar{l}_{i}\right)}{l_{i}^{*}\left(s_{i}, \bar{l}_{i}\right)^{1-\alpha} k_{i}^{*}\left(s_{i}, \bar{l}_{i}\right)^{\alpha}}
$$

Absent misallocation, farm-level MPLa and TFPR should equal to their zone-level average and any deviation from zone average indicates misallocation. A land reform that reduces misallocation moves farm-level efficiency gain towards unity and MPLa and TFPR toward their zone average.

\section{Empirical Evidence}

We document the empirical association between changes in land market activity and productivity and use a standard difference-in-difference strategy to study the causal effects of a land certification reform on rentals and productivity. Our analysis exploits the variation in the granting of land certificates across time and space in Ethiopia as a result of the decentralized implementation of the policy.

\subsection{Land Rentals and Misallocation}

To document the association between changes in land market activity and productivity, we separate zones into two groups. A first group that consists of zones for which the share of rented land, $R_{z}$, does not increase between 2013/14 and 2015/16, and a second group that 
Table 2: Land Rental Markets, Misallocation, and Productivity

\begin{tabular}{lccc}
\hline \multirow{2}{*}{ Dependent variable: } & \multicolumn{3}{c}{ Farm-Level Misallocation } \\
& Efficiency Gain & MPLa & TFPR \\
\hline Land Rentals, $\psi$ & -0.134 & -0.191 & -0.152 \\
& $(0.049)$ & $(0.065)$ & $(0.065)$ \\
Observations & 4,712 & 4,712 & 4,712 \\
$R^{2}$ & 0.23 & 0.12 & 0.16 \\
\hline
\end{tabular}

Notes: Results of regression (8) for the following measures of farm-level misallocation: (1) efficiency gain $\left|\log \left(e_{i z t}\right)\right|,(2)$ marginal product of land relative to the zone-level average, $\left|\log \left(\mathrm{MPLa}_{i z t} / \overline{\mathrm{MPLa}}_{z t}\right)\right|$, (3) revenue productivity relative to the zone-level average, $\left|\log \left(\mathrm{TFPR}_{i z t} / \overline{\mathrm{TFPR}}_{z t}\right)\right|$. Standard errors are calculated using block-bootstrap clustering at the zone level and are reported in parentheses. Data from Ethiopia ISA 2013/14 and 2015/16 waves.

consists of those zones for which land rentals increase in that period. We are interested in assessing whether there are differential changes over time in productivity across these two groups of zones, and by how much.

We focus on the following empirical specification:

$$
m_{i z t}=\alpha_{z}+\lambda_{t}+\psi d_{z t}+\beta \log \mathrm{TFP}_{i z}+\varepsilon_{i z t},
$$

where $m_{i z t}$ is a measure of the degree of misallocation for farm $i$ in zone $z$ and time $t, \alpha_{z}$ is a zone fixed effect, $\lambda_{t}$ is a year fixed effect, and dummy $d_{z t}$ captures changes in land rentals. In the zones where the land market activity increases across waves the indicator variable $d_{z t}$ equals one in the second wave, and in the control zones $d_{z t}$ equals zero. The parameter of interest is $\psi$, which captures how changes in land rentals relate to changes in individual farmlevel misallocation. We also control for the permanent component of individual farm-level TFP.

We use three specific measures of farm-level misallocation: (a) farm-level efficiency gain, $\left|\log \left(e_{i z t}\right)\right|$; (b) farm-level marginal product of land relative to the zone-level average, $\left|\log \left(\mathrm{MPLa}_{i z t} / \overline{\mathrm{MPLa}}_{z t}\right)\right|$; and (c) farm-level revenue productivity relative to the zone-level 
average, $\left|\log \left(\mathrm{TFPR}_{i z t} / \overline{\mathrm{TFPR}}_{z t}\right)\right|$. Notice that we consider the absolute value of the log measures of misallocation since the farm-level ratios can be larger or smaller than one (positive or negative in the $\log$ ) both of which indicate misallocation. As a result, we can unambiguously interpret a negative estimate for $\psi$ as a movement towards efficiency (less misallocation).

Our findings are reported in Table 2. Using farm-level efficiency gains, we find that land rentals are associated with a significant decline in resource misallocation. The increase in land rentals is related to a decline in efficiency gains with a significant coefficient of $\psi$ equal to -0.134 . The estimated $\psi$ using the other measures of farm-level misallocation, MPLa and TFPR, is also negative and significant with respective values of -0.191 and -0.152 . Standard errors are calculated using block-bootstrap clustering at the zone level and are reported in the parentheses. Further, our results continue to hold if we additionally control for other household characteristics or potential output market frictions, see Appendix C. Finally, note that the fact that we exploit variation across zones and over time underscores alternative explanations for the relationship between land rentals and misallocation such as mis-specification or measurement error in inputs or output. We now turn to the effects of the land certification reform.

\subsection{Land Certification Effects on Rentals and Productivity}

We study the effects of the land certification reform on rentals and productivity. Particularly, we exploit variation across regions and over time arising from the decentralized reform implementation in order to identify the causal effects. We start by showing how the certification reform facilitates rentals, followed by assessing how the certification reform affects 
productivity and reduces misallocation.

Land certification and rentals. As we previously discussed, rentals and certification shares are highly correlated at the zone level. We now use the variation in the certification reform to identify the causal link between certification and rentals. We separate zones into two groups in our sample according to their changes in certification shares across waves. We define the treatment group consisting of zones for which the share of certified land parcels, $C_{z}$, increases between $2013 / 14$ and $2015 / 16$. The control group consists of zones for which the share does not increase. We then focus on the difference-in-difference specification at the zone level as follows:

$$
R_{z t}=\alpha_{z}+\lambda_{t}+\psi^{C} d_{z t}^{C}+\varepsilon_{z t},
$$

with the treatment dummy $d_{z t}^{C}$ capturing changes in certificates. The variable of interest on the left-hand-side is the share of rented land in zone $z$ at time $t$. We find that the estimated coefficient $\psi^{C}=0.053$ with a clustered standard error of 0.023 . This indicates that land certification is associated with 5.3 percentage points higher rental share, and the effect is statistically significant. ${ }^{5}$ In addition, we can also assess the effect of treatment intensity by changing the treatment dummy $d_{z t}^{C}$ from zero or one to the changes in certification shares in 2015/16 wave. The coefficient (standard error) in this case is 0.134 (0.067), indicating that the intensive margin also matters, with one more percentage point of certification shares increasing rentals by 0.13 percentage point.

Land certification and misallocation. We have established that land certification facilitates rentals, which could reduce misallocation and increase productivity. We assess this

\footnotetext{
${ }^{5}$ Note that we assess the relationship in equation (9) at the zone level instead of at the farm level since a large proportion of farms have zero rented land. Nevertheless, we find a similar positive relationship at the farm level using farm-level rental shares as the rent in land over operated land for each farm.
} 
Table 3: Effects of Land Certification on Rentals and Productivity

\begin{tabular}{lcccc}
\hline Dependent variable & Rentals & \multicolumn{3}{c}{ Farm-Level Misallocation } \\
& & Efficiency Gain & MPLa & TFPR \\
Land Certificates, $\psi^{C}$ & 0.053 & -0.110 & -0.170 & -0.094 \\
& $(0.023)$ & $(0.049)$ & $(0.064)$ & $(0.065)$ \\
Observations & 138 & 4,712 & 4,712 & 4,712 \\
$R^{2}$ & 0.89 & 0.23 & 0.12 & 0.16 \\
\hline
\end{tabular}

Notes: Results of regressions (9) and (10) for zone level land rental shares and for three measures of farm-level misallocation: (a) efficiency gains, (b) marginal product of land, (c) revenue productivity, with treatment and control groups refer to zones with increasing/non-increasing certification shares. Standard errors are calculated using block-bootstrap clustering at the zone level and are reported in parentheses. Data from Ethiopia ISA 2013/14 and 2015/16 waves.

effect through the difference-in-difference specification as follows:

$$
m_{i z t}=\alpha_{z}+\lambda_{t}+\psi^{C} d_{z t}^{C}+\beta \log \operatorname{TFP}_{i z}+\varepsilon_{i z t},
$$

with the treatment dummy $d_{z t}^{C}$ capturing changes in land certification shares. The variables of interest $m_{i z t}$ are the measures of farm-level misallocation. Results are reported in Table 3, together with standard errors from block-bootstrap clustering at the zone level. The land certification reform significantly reduces efficiency gains with a coefficient of $\psi^{C}$ equal to $-0.110 .{ }^{6}$ Similar results arise using the other measures of farm-level misallocation. We highlight that the coefficients associated with land certification are substantially smaller in magnitude compared to the coefficients associated with land rentals. This suggests that not all of the association between rentals and misallocation is explained by certification reform, or put differently, the causal effects of certification reform do not capture the overall effect of land markets on misallocation and productivity. There may be other frictions beyond the lack of land certificates that also affect rentals and allocative efficiency, and there may be

\footnotetext{
${ }^{6}$ We also assess the intensive margin of the treatment - a one precentage point higher land certification share reduces efficiency gains by 0.19 percent, although the effect is not significant due to large standard errors.
} 
a lag between the granting of certificates and land reallocation. While our analysis cannot empirically identify the causal effect of rentals on misallocation since rentals are endogenous and may depend on other factors, we study this issue in our quantitative analysis.

Pre-trend analysis. One potential concern of interpreting the difference-in-difference results as causal is on the differences in pre-trends between the treatment and control groups. For instance, we may suspect that zones with increasing rentals between 2013/14 and 2015/16 due to the certification reform may also experience increasing rentals before the 2013/14 wave because of other factors. In other words, if there are pre-trends in rentals or misallocation between the treatment and control groups, then the variation of certification may not be exogenous. To check for pre-trends, we make use of the available earlier wave in 2011/12. ${ }^{7}$ We plot the time evolution of differences between the treatment and control groups in the land rental share and our three measures of misallocation for the 2011/12, 2013/14, and 2015/16 waves in Figure 1. Note that the treatment and control groups are defined as before by zones with increasing or non-increasing certification shares between the 2013/14 and 2015/16 waves, and hence the change between 2011/12 and 2013/14 represent pre-trends. We do not find significant differences in rental shares or misallocation between the treatment and control groups between 2011/2012 and 2013/2014 waves, while differences in rental shares and misallocation measures emerge between the 2013/14 and 2015/16 wave.

To more rigorously assess that the treatment and control groups share the same trend before 2013/14 wave, we conduct a placebo test following Nunn and Qian (2011). We consider the difference-in-difference specification between land certification and rentals using the same

\footnotetext{
${ }^{7}$ We do not use the 2011/12 wave in our main analysis because this wave does not report farm output. However, the 2011/12 wave is sufficient for the pre-trend analysis since farm factor inputs and other variables are recorded. Together with our fixed-effect measure of farm productivity, we use farm inputs to calculate the implied output and the three measures of misallocation.
} 
Figure 1: Pre-Trends of Group Differences on Rentals and Misallocation

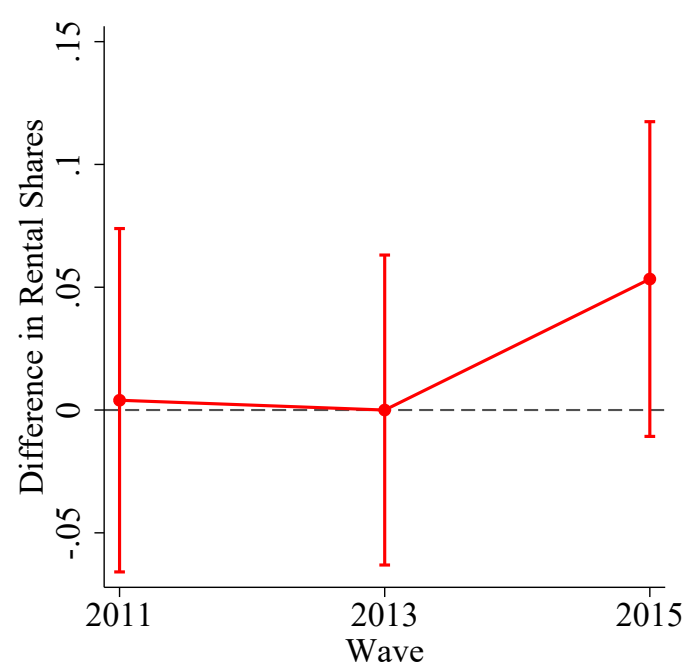

(a) Rental Shares

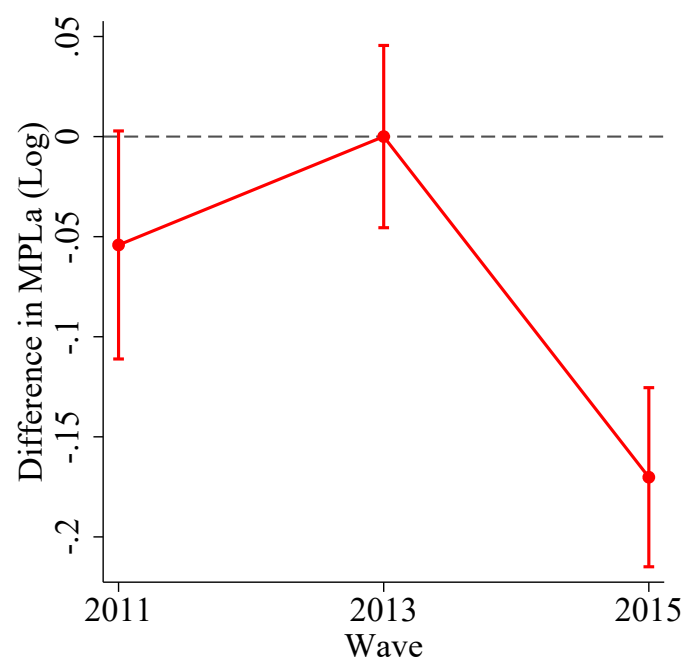

(c) Marginal Product of Land

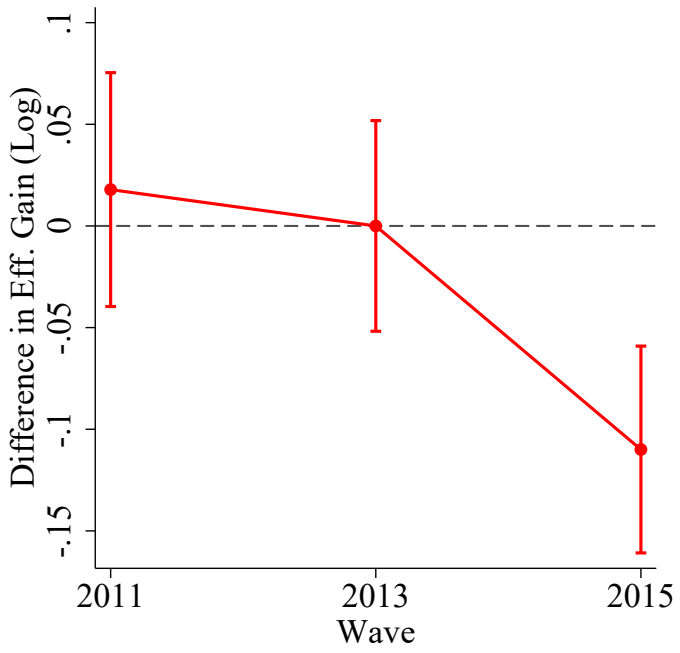

(b) Efficiency Gain

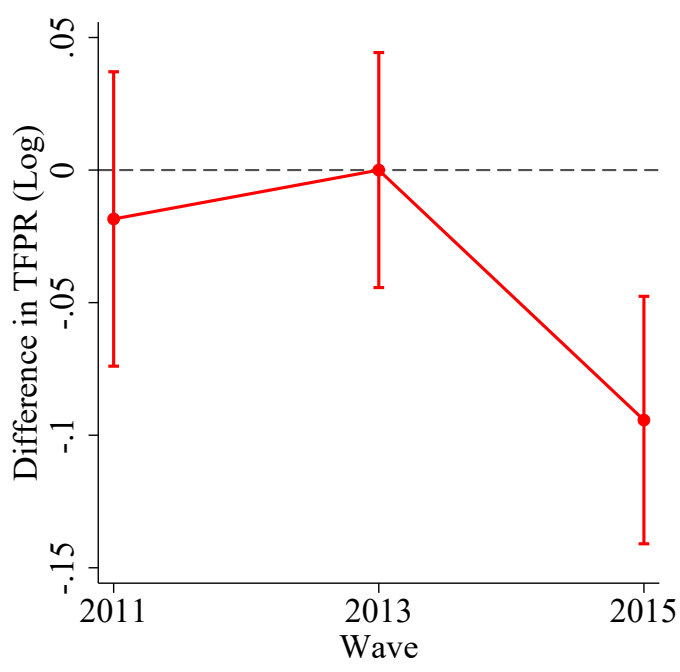

(d) Revenue Productivity

Note: Differences between the treatment and control groups for variables of interest over three waves of data: 2011/12, 2013/14, and 2015/16. Treatment and control groups are defined over increasing/non-increasing certification shares between 2013/14 and 2015/16 waves, and hence the change between 2011/12 and 2013/14 represent pre-trends. We normalize differences relative to the 2013/14 wave. 
assignment of zones into treatment and control groups according to increasing/non-increasing land certification between 2013/14 and 2015/16 waves, but applied to the 2011/12 and 2013/14 waves. In other words, we assign the treatment dummy $d_{z t}^{C}=1$ in 2013/14 (placebo treatment) for zones in which land certification increases between 2013/14 and 2015/16 and $d_{z t}^{C}=0$ in 2011/12; and $d_{z t}^{C}=0$ for both $2011 / 12$ and 2013/14 for the control group. The rationale is that if there are pre-trends before 2013/14 for those zones with increasing land certification between 2013/14 and 2015/16, we should identify the pre-trends in this placebo test. We find, however, that the coefficient $\psi^{C}$ for this placebo test is insignificant for land rentals and for all three measures of misallocation, with estimated coefficients of -0.011 $(0.035),-0.023(0.048), 0.044(0.086)$, and $0.015(0.088)$. These results suggest that the variation in land certification that we study is largely exogenous across zones and over time and, hence, useful in interpreting the empirical effects on land rentals and misallocation.

\section{Quantitative Analysis}

We study the quantitative effects of land markets using our macroeconomic framework in which land rentals are endogenously determined by the institutional barriers to land markets. First, we assess the effects of a policy reform that consists of a reduction in the institutional barriers to land markets on resource allocation and productivity. Second, we perform counterfactual policy experiments on the institutional barriers, which we directly relate to the extent of land certification in the economy. We show that a counterfactual full certification policy accounts for just one-fourth of the overall productivity gains from land rentals. 


\subsection{Calibration}

We calibrate the model of each zone to match observations for Ethiopia in the 2013/14 wave. In addition to the two factor share parameters already discussed $(\alpha=0.274$ and $\gamma=$ 0.536), we need to determine productivity and land endowments $\left(s_{i}, \bar{l}_{i}\right)$ for farm households in each zone and the two institutional cost parameters $\left(\chi_{z}^{q}\right.$ and $\left.\chi_{z}^{f}\right)$. We use the estimates of productivity already discussed for household farms in each zone. For land endowments, our data provide information on farm size based on the operational scale of each farm, in addition to rent-in and rent-out land. The land endowment is then calculated as the operational scale minus land rented in plus land rented out. Note that in the data, the total size of rent-out land is, however, smaller than that of the rent-in. This may be due to the survey design, which is based on land parcels being operated, including both owned and rented in parcels; or that farmers renting out land are more likely to exit the sample. We hence scale up our calculated land endowments such that the sum of land endowments matches that of operational land in each zone.

Recall that the institutional cost parameters $\chi_{z}^{q}$ and $\chi_{z}^{f}$, which represent barriers to land rental markets such as the granting of land certificates (or their lack of) or implicit institutional barriers to land markets, are endogenously related to the extensive and intensive margins of land rentals in the model such that a reduction in these barriers generate an increase in land rentals. We exploit this theoretical relationship to calibrate these barrier parameters. In particular, for each zone, we choose $\chi_{z}^{q}$ and $\chi_{z}^{f}$ to jointly match two moments in the data: the fraction of rented land $R_{z}$ and the percentage of households renting in land. Note that because we have a discrete number of farmers in each zone, we choose the lowest 
fixed cost $\chi_{z}^{f}$ that delivers the data target for the percentage of households who rent in land. Similarly, for zones with zero rentals, we choose the smallest $\chi_{z}^{f}$ that achieves zero rentals. In this case the value of $\chi_{z}^{q}$ is irrelevant. The calibrated model matches exactly the targeted moments. We refer to the calibrated equilibrium allocations as status quo.

\subsection{The Role of Land Markets}

In order to assess the effects of land markets on resource allocation and productivity, we conduct a policy experiment on the status quo allocations. We implement an unexpected change in the institutional costs, $\chi_{z}^{q}, \chi_{z}^{f}$, that is, we change these parameters by zone so as to match the fraction of rented land and the percentage of rent-in households for the 2015/16 wave. We then compute the implied equilibrium allocations at the farm level that result from this change in institutional costs and we denote these allocations as reform.

We assess the model implied relationship between land rentals and misallocation measures, and how it compares with the empirical results. Note that in each of status quo and reform, the model generates a set of operational land scales $l_{i}^{*}$ together with capital input and output $k_{i}^{*}$ and $y_{i}^{*}$ for each zone. We use the model-generated data $l_{i}^{*}, k_{i}^{*}, y_{i}^{*}$ to calculate our three measures of misallocation, and implement the difference-in-difference specification in equation (8).

The results are reported in panel (a) of Table 4 and indicate that the model-generated data results in similar empirical findings. For instance, increasing land rentals at the zone level leads to a 12.6 percent reduction in farm-level efficiency gain in the model-generated data, compared to 13.4 percent in the empirical data. Hence, the calibrated model with land 
Table 4: The Effects of Land Markets on Productivity in the Model

(a) Rentals and Misallocation

\begin{tabular}{lccc}
\hline Dependent variable: & \multicolumn{3}{c}{ Farm-Level Misallocation } \\
& Efficiency Gain & MPLa & TFPR \\
\hline Land Rentals, $\psi$ & -0.126 & -0.152 & -0.111 \\
& $(0.018)$ & $(0.023)$ & $(0.017)$ \\
Observations & 4,712 & 4,712 & 4,712 \\
$R^{2}$ & 0.44 & 0.36 & 0.36 \\
\hline
\end{tabular}

(b) Land Certification and Rentals/Misallocation

\begin{tabular}{lcccc}
\hline Dependent variable: & Rental Share & \multicolumn{3}{c}{ Farm-Level Misallocation } \\
& & Efficiency Gain & MPLa & TFPR \\
\hline Land Certification, $\psi^{C}$ & 0.053 & -0.077 & -0.097 & -0.070 \\
& $(0.023)$ & $(0.025)$ & $(0.029)$ & $(0.021)$ \\
Observations & 138 & 4,712 & 4,712 & 4,712 \\
$R^{2}$ & 0.89 & 0.44 & 0.36 & 0.36 \\
\hline
\end{tabular}

Notes: Panel (a) shows results of regression (8) between rentals and misallocation calculated using modelgenerated data, and panel (b) shows the results of regression (9) and (10) between land certification, land rentals, and misallocation, with land rentals and misallocation calculated using model-generated data. Standard errors are calculated using block-bootstrap clustering at the zone level and are reported in parentheses.

institutional costs captures well the empirical association between changes in land rentals and productivity.

We also assess the relationship between land certification and model-generated misallocation and how it compares with the empirical relationship. We use the model-generated allocations for each zone $l_{i}^{*}, k_{i}^{*}, y_{i}^{*}$ to calculate our three measures of misallocation, and implement the difference-in-difference specification in equation (10), with the misallocation measures as dependent variables and the treatment/control groups defined by zones with increasing and non-increasing land certification shares directly from data. The results are reported in panel (b) of Table 4 . We find that land certification significantly reduces misallocation in the model-generated data, although the magnitudes are slightly lower than that of the empirical data. 
We highlight that our policy experiment, which is solely based on changes in $\chi_{z}^{q}$ and $\chi_{z}^{f}$ to match variation over time in rentals by zone, does not target the empirical relationships between certification, rentals, and misallocation. For instance, if we abstract from the quadratic rental costs $\left(\chi_{z}^{q}=0\right)$ and increase the fixed cost $\left(\chi_{z}^{f}\right)$ to match the same zonelevel land rental shares, then the estimated coefficient in the model is substantially lower in magnitude compared to the data. The only relationship that is implicitly targeted in our experiment is the relationship between certification shares and rentals since we directly use the certification share data and we match the statistics on rentals by zone.

\subsection{Land Certification, Rental Costs, and Misallocation}

In order to characterize how certification reform translates into changes in institutional barriers, we estimate the empirical relationship between the institutional cost parameters and land certification using the panel data. In particular, we estimate

$$
\log \chi_{z t}^{c}=\alpha^{c}+\lambda_{t}^{c}+\beta^{c} C_{z t}+\varepsilon_{z t}^{c}, \quad c \in\{q, f\}
$$

where $\alpha^{c}$ is the intercept common across zones, $\lambda_{t}^{c}$ is the time trend that is common to all zones, $\beta^{c}$ is the elasticity between land certification shares $\left(C_{z t}\right)$ and the cost parameter, and $\varepsilon_{z t}^{c}$ is an error term for each of the quadratic and fixed costs parameters. We find an elasticity $\beta^{q}=-1.821$ with a standard error of 0.555 . This indicates that one percentage point higher certification share is significantly associated with 1.8 percent lower quadratic

cost parameter. We find an elasticity $\beta^{f}=-2.097$ with a standard error of 0.676 , and hence land certification also reduces the fixed cost parameter. These results conform with the traditional view that land certification reforms help reduce obstacles to land market activity. 
Interestingly, we find that the timing of land certification also matters. The data include information on the year that land certification is granted for each parcel of land, which we use to calculate the median number of years since certification in a zone. We then regress in logs zone-level changes in institutional costs on years since certification. We find that institutional fixed costs decline faster with more years since certification, an elasticity of -1.815 with standard error of 0.757 . The effect on the quadratic adjustment cost parameter is insignificant. This result suggest a lag between certification and land reallocation.

Land market activity is crucial in facilitating the efficient allocation of land among farmers and improving agricultural productivity. Empirically, we have established that certification reform increases land rentals and alleviates misallocation. This effect from certification reform, however, does not fully capture the overall effect from rentals since there are other frictions or lagging behavior affecting rental market activity. We use our quantitative model to assess the contribution of certification reform and other frictions to misallocation and productivity for a full range of scenarios for both certification and rental market activity which are not necessarily observed in the data.

We use our empirical estimates of the elasticity of institutional costs to certification shares to compute a range of institutional costs for each zone spanning no certification to full certification. We compute the counterfactual institutional cost as:

$$
\hat{\chi}_{z}^{c}\left(\hat{C}_{z}\right)=\chi_{z}^{c}+\beta^{c}\left(\hat{C}_{z}-C_{z}\right), \quad c \in\{q, f\}, \quad \hat{C}_{z} \in[0,1],
$$

where $\chi_{z}^{c}$ 's are the calibrated cost parameters, $C_{z}$ are the land certification shares, and $\beta^{c}$ is the elasticity for the quadratic and fixed cost estimated in equation (11).

Using the implied institutional costs in each zone for the extreme cases of full certification 
and no certification, we calculate the associated zone-level output. We then calculate the ratio of zone-level output between the full certification and the no certification cases. We find the output ratio to be 1.110 on average across zones. That is, a full certification reform increases zone-level agricultural productivity by 11 percent on average.

We now put these results in the context of the overall effects from land rentals that arise from a counterfactual scenario from no rentals to the efficient level of rentals. Recall that the institutional cost parameters $\chi_{z}^{q}$ and $\chi_{z}^{f}$ capture all possible frictions affecting land rental activity. By increasing these cost parameters to arbitrarily high values, we can completely shut down rental activity in each zone. Similarly, we can also set these cost parameters to zero to obtain the efficient levels of rentals. In each case, we use the implied allocations to compute zone-level output. We find the zone-level output ratio between efficient rentals and no rentals to be 1.433 on average across zones, that is, reforming each zone from no rentals to efficient rentals increases zone-level agricultural productivity by 43.3 percent on average. Comparing this gain to the effect of full certification reform, we find that the effect of certification is $\log (1.110) / \log (1.433)=29$ percent of the overall effect of rentals. That is, land certification policies account for roughly one fourth of the overall effects of land markets. Our results highlight the importance of comprehensive land reforms in poor countries that alleviate other frictions impeding land market activities, in addition to granting certificates, which has been the focus of most land reforms and previous analyses in the literature. 


\section{The Effects of Land Markets on Inequality}

Our analysis shows that active land markets imply higher efficiency in resource allocation and productivity, but a common and important concern for policy makers is that opening land markets might result in higher inequality (Deininger and Binswanger, 1999; André and Platteau, 1998; Otsuka, 2007). The idea is that land markets might concentrate land and farm income among few farmers. We use our quantitative model to assess the effects of land certification reform on farm income inequality in Ethiopia.

An empirical assessment of the effects of land certification reform on income inequality is challenging in terms of data requirements. First, the assessment requires data on both land rental payments paid and received by each farm. Second, the assessment also requires that the sum of rental payments paid by those that rent in land be identical to the total receipts from renting out land, which can also be an important constraint for non-administrative survey data. Unfortunately, although our data contain the payments paid by farmers that rent in land, it does not collect the data on income generated from renting out land. In addition, it is possible that some households renting out are not even in the survey, as in practice the share of land rented in is larger than that of renting out. Fortunately, our modelgenerated status quo and reform allocations resulting changes institutional costs satisfy the requirements to analyze inequality and can be related to the land certification reform.

We construct measures of within-zone inequality for farm income separately in the status quo and reform allocations using a definition of farm income that is the sum of farm production (value added) minus capital factor payments and land rental costs. Recall that land rental costs incorporate the possibility of non-negative income generated from renting 
Table 5: Effects of Land Reform on Poverty and Inequality

\begin{tabular}{lcccccc}
\hline Dependent variable: & \multicolumn{2}{c}{ Inequality } & \multicolumn{3}{c}{ Average farm income } \\
& Variance & $90-10$ & & Bottom & Top \\
& of logs & ratio & 10 & 25 & 50 & 10 \\
\hline Land Certification, $\psi^{C}$ & -0.025 & -0.036 & 0.101 & 0.050 & 0.035 & 0.030 \\
& $(0.031)$ & $(0.039)$ & $(0.053)$ & $(0.034)$ & $(0.021)$ & $(0.017)$ \\
Observations & 138 & 138 & 138 & 138 & 138 & 138 \\
$R^{2}$ & 0.96 & 0.97 & 0.96 & 0.98 & 0.99 & 0.99 \\
\hline
\end{tabular}

Notes: We calculate measures of farm income dispersion at the zone-level: variance of log and the 90-10 percentile ratio, and estimate the impact of the land certification reform on income inequality in equation (12) at the zone level using model-generated data. We also calculate the average (log) farm income of the bottom 10, 25, 50 percent of farmers and the top 10 percent of farmers and estimate the impact of the certification reform. Standard errors are in parentheses. We control for zone fixed effects in all regressions.

out land. Based on this income measure, we construct two broadly-used measures of income inequality: the variance of log farm income and the $90-10$ percentile ratio, and run the following difference-in-difference specification:

$$
\text { Inequality }_{z t}=\alpha_{z}+\lambda_{t}+\psi^{C} d_{z t}^{C}+\varepsilon_{z t}
$$

where the treatment zones are defined as those for which there is an increase in the land certification shares as in our empirical analysis. Table 5 reports the results which shows no evidence that the land certification reform increases inequality, in fact there is a slight decrease.

To better understand the effect of the reform on the distribution of farm income, we also run a specification with zone-level average (log) farm income for the poorest 10, 25, and 50 percent of farmers; and the richest 10 percent of farmers as dependent variables. We find that the land reform substantially increases farm income at the very bottom of the income distribution. In particular, land certification increases average income significantly by 10.1 percent for the poorest 10 percent of farmers, by 5 and 3.5 percent for the poorest 
25 and 50 percent farmers, whereas average income of the richest 10 percent of farmers also increases but by only 3 percent. The economic intuition behind this result is that, despite agricultural production and profits being more concentrated among productive (high income) farms with the reform, less productive (poor) farmers benefit the most by the positive land rental income.

We conclude that, contrary to the conventional wisdom that land reform increases income inequality, in our model the land certification reform substantially reduces poverty by increasing income the most among the poorest farm households.

\section{Conclusions}

We show that land rentals provide a useful mechanism to overcome imbalances between the allocation of land-use rights and the efficient operational scale of farms. First, exploiting a land certification reform in Ethiopia, we show empirically that land certification generates an increase in rentals and productivity. Second, using a quantitative theory consistent with the empirical findings, we show that land certifications only partially capture the overall effects of rentals. Specifically, we find that a full certification reform accounts for just one-fourth of the overall productivity gains from land rentals understood as the reallocation gain from no rentals to efficient rentals. Our results highlight the importance of comprehensive reforms that alleviate frictions to land transactions beyond the granting of land certificates.

Despite the strong positive effects of land markets on resource allocation and agricultural productivity, the land certification reform has had arguably limited impact insofar as land markets are still underdeveloped in Ethiopia. The limited use of land rentals can arise from 
various frictions that are not necessarily removed by issuing land certificates, which may include restrictions on other factor inputs, other imperfections in land markets (e.g., restrictions on rentals and sales), regulations, or weak legal institutions that limit the credibility of the land reform, among others.

Although our analysis strictly belongs to the context of land rental market activity in Ethiopia, we think our results highlight the general importance of comprehensive land reforms in poor countries that address the effective tradability of land in order to promote better resource allocation, going beyond land certification which has been the main focus in most reform episodes. We hope that our work generates further research on the broader effects of land market activity and its limitations in other contexts.

\section{References}

Acemoglu, D., Johnson, S., and Robinson, J. A. (2001). The colonial origins of comparative development: An empirical investigation. American Economic Review, 91(5):1369-1401.

Adamopoulos, T. (2011). Transportation costs, agricultural productivity, and cross-country income differences. International Economic Review, 52(2):489-521.

Adamopoulos, T., Brandt, L., Leight, J., and Restuccia, D. (2017). Misallocation, selection, and productivity: A quantitative analysis with micro data from China. Working Paper.

Adamopoulos, T. and Restuccia, D. (2014). The size distribution of farms and international productivity differences. American Economic Review, 104(6):1667-1697.

André, C. and Platteau, J.-P. (1998). Land relations under unbearable stress: Rwanda caught in the malthusian trap. Journal of Economic Behavior 83 Organization, 34(1):1 47.

Banerjee, A. and Iyer, L. (2005). History, institutions, and economic performance: The legacy of colonial land tenure systems in India. American Economic Review, 95(4):11901213.

Banerjee, A. V., Gertler, P. J., and Ghatak, M. (2002). Empowerment and efficiency: Tenancy reform in West Bengal. Journal of Political Economy, 110(2):239-280.

Behrman, J. R. (1999). Chapter 43 labor markets in developing countries. volume 3 of Handbook of Labor Economics, pages 2859 - 2939. Elsevier.

Besley, T. and Burgess, R. (2000). Land reform, poverty reduction, and growth: Evidence from india. The Quarterly Journal of Economics, 115(2):389-430. 
Brooks, W., Donovan, K., and Johnson, T. R. (2020). From micro to macro in an equilibrium diffusion model. Working Paper.

Bryan, G., Chowdhury, S., and Mobarak, A. M. (2014). Underinvestment in a Profitable Technology: The Case of Seasonal Migration in Bangladesh. Econometrica, 82(5):16711748.

Bryan, G. and Morten, M. (2019). The Aggregate Productivity Effects of Internal Migration: Evidence from Indonesia. Journal of Political Economy, (forthcoming).

Burchardi, K. B., Gulesci, S., Lerva, B., and Sulaiman, M. (2018). Moral Hazard: Experimental Evidence from Tenancy Contracts. The Quarterly Journal of Economics, 134(1):281-347.

Chari, A. V., Liu, E. M., Wang, S.-Y., and Wang, Y. (2020). Property rights, land misallocation and agricultural efficiency in China. Review of Economic Studies, forthcoming.

Chen, C. (2017). Untitled land, occupational choice, and agricultural productivity. American Economic Journal: Macroeconomics, 9(4):91-121.

Chen, C. (2020). Technology adoption, capital deepening, and international productivity differences. Journal of Development Economics, 143:102388.

de Janvry, A., Emerick, K., Gonzales-Navarro, M., and Sadoulet, E. (2015). Delinking land rights from land use: Certification and migration in Mexico. American Economic Review, 105.

De Magalhães, L., Martorell, E., and Santaeulàlia-Llopis, R. (2019). Progressivity and Development. Working papers, Barcelona GSE.

De Magalhães, L. and Santaeulàlia-Llopis, R. (2018). The Consumption, Income, and Wealth of the Poorest: An Empirical Analyisis of Economic Inequality in Rural and Urban SubSaharan Africa for Macroeconomists. Journal of Development Economics, 134:350-371.

Deininger, K. (2003). Land Markets in Developing and Transition Economies: Impact of Liberalization and Implications for Future Reform. American Journal of Agricultural Economics, 85(5):1217-1222.

Deininger, K., Ali, D. A., and Alemu, T. (2008). Assessing the functioning of land rental markets in Ethiopia. Economic Development and Cultural Change, 57(1):67-110.

Deininger, K. and Binswanger, H. (1999). The Evolution of the World Bank's Land Policy: Principles, Experience, and Future Challenges. World Bank Research Observer, 14(2):247276.

Deininger, K. and Feder, G. (2001). Land institutions and land markets. In Agricultural Production, volume 1 of Handbook of Agricultural Economics, pages 287 - 331. Elsevier.

Donovan, K. (2020). The equilibrium impact of agricultural risk on intermediate inputs and aggregate productivity. Review of Economic Studies, forthcoming.

ELTAP (2007). Study on The Assessment of Rural Land Valuation and Compensation Practices in Ethiopia: Final Main Report.

Giné, X. (2005). Cultivate or Rent Out? Land Security in Rural Thailand. Policy Research Working Paper Series 3734, The World Bank. 
Gollin, D., Lagakos, D., and Waugh, M. E. (2014). Agricultural productivity differences across countries. American Economic Review: Papers and Proceedings, 104(5):165-170.

Gollin, D., Parente, S. L., and Rogerson, R. (2002). The role of agriculture in development. American Economic Review: Papers and Proceedings, 92(2):160-164.

Gollin, D., Parente, S. L., and Rogerson, R. (2004). Farm work, home work and international productivity differences. Review of Economic Dynamics, 7(4):827-850.

Gollin, D., Parente, S. L., and Rogerson, R. (2007). The food problem and the evolution of international income levels. Journal of Monetary Economics, 54(4):1230-1255.

Gollin, D. and Udry, C. (2017). Heterogeneity, measurement error, and misallocation: Evidence from african agriculture. Working Paper.

Goodman-Bacon, A. (2019). Difference-in-difference with variation in treatment timing. Working Paper.

Hendricks, L. and Schoellman, T. (2018). Human capital and development accounting: New evidence from wage gains at migration. The Quarterly Journal of Economics, 133(2):665700 .

Holden, S. T. and Ghebru, H. (2016). Land rental market legal restrictions in Northern Ethiopia. Land Use Policy, 55(Supplement C):212 - 221.

Hsieh, C.-T. and Klenow, P. J. (2009). Misallocation and manufacturing TFP in China and India. Quarterly Journal of Economics, 124(4):1403-1448.

Kinnan, C. (2019). Distinguishing barriers to insurance in Thai villages. Technical report.

Kinnan, C. and Townsend, R. (2012). Kinship and Financial Networks, Formal Financial Access, and Risk Reduction. American Economic Review, 102(3):289-293.

Lagakos, D., Mobarak, A. M., and Waugh, M. E. (2018). The Welfare Effects of Encouraging Rural-Urban Migration. NBER Working Papers 24193, National Bureau of Economic Research, Inc.

Lagakos, D. and Waugh, M. E. (2013). Selection, agriculture, and cross-country productivity differences. American Economic Review, 103(2):948-980.

Meghir, C., Mobarak, A. M., Mommaerts, C. D., and Morten, M. (2019). Migration and Informal Insurance. NBER Working Papers 26082, National Bureau of Economic Research, Inc.

Mobarak, A. M. and Rosenzweig, M. (2014). Risk, Insurance and Wages in General Equilibrium. CEPR Discussion Papers 9797, C.E.P.R. Discussion Papers.

Morten, M. (2019). Temporary Migration and Endogenous Risk Sharing in Village India. Journal of Political Economy, 127(1):1-46.

Munshi, K. and Rosenzweig, M. (2016). Networks and misallocation: Insurance, migration, and the rural-urban wage gap. American Economic Review, 106(1):46-98.

Nunn, N. and Qian, N. (2011). The Potato's Contribution to Population and Urbanization: Evidence From A Historical Experiment*. The Quarterly Journal of Economics, 126(2):593-650. 
Ostrom, E. (2010). Beyond Markets and States: Polycentric Governance of Complex Economic Systems. American Economic Review, 100(3):641-672.

Otsuka, K. (2007). Chapter 51 efficiency and equity effects of land markets. In Evenson, R. and Pingali, P., editors, Agricultural Development: Farmers, Farm Production and Farm Markets, volume 3 of Handbook of Agricultural Economics, pages 2671-2703. Elsevier.

Restuccia, D. and Rogerson, R. (2017). The causes and costs of misallocation. Journal of Economic Perspectives, 31(3).

Restuccia, D. and Santaeulàlia-Llopis, R. (2017). Land Misallocation and Productivity. Working Paper 23128, National Bureau of Economic Research.

Restuccia, D., Yang, D. T., and Zhu, X. (2008). Agriculture and aggregate productivity: A quantitative cross-country analysis. Journal of Monetary Economics, 55(2):234-250.

Rosenzweig, M. R. (1978). Rural Wages, Labor Supply, and Land Reform: A Theoretical and Empirical Analysis. American Economic Review, 68(5):847-861.

Rosenzweig, M. R. (1988). Labor markets in low-income countries. In Chenery, H. and Srinivasan, T., editors, Handbook of Development Economics, volume 1 of Handbook of Development Economics, chapter 15, pages 713-762. Elsevier.

Rosenzweig, M. R. and Stark, O. (1989). Consumption Smoothing, Migration, and Marriage: Evidence from Rural India. Journal of Political Economy, 97(4):905-926.

Rosenzweig, M. R. and Wolpin, K. I. (1985). Specific Experience, Household Structure, and Intergenerational Transfers: Farm Family Land and Labor Arrangements in Developing Countries. The Quarterly Journal of Economics, 100(Supplemen):961-987.

Sadoulet, E., de Janvry, A., and Fukui, S. (1997). The meaning of kinship in sharecropping contracts. American Journal of Agricultural Economics, 79(2):394-406.

Shaban, R. A. (1987). Testing between competing models of sharecropping. Journal of Political Economy, 95(5):893-920.

Townsend, R. M. (1994). Risk and insurance in village India. Econometrica, 62(3):539-591.

Udry, C. (1994). Risk and Insurance in a Rural Credit Market: An Empirical Investigation in Northern Nigeria. Review of Economic Studies, 61(3):495-526.

Valentinyi, A. and Herrendorf, B. (2008). Measuring factor income shares at the sectoral level. Review of Economic Dynamics, 11(4):820-835. 


\section{Online Appendix}

\section{A Ethiopia LSMS-ISA Data}

Agricultural output. Farm output is recorded in physical quantities (kilograms) of different crops. Some farmers may not have finished harvesting at the time of the survey. In those cases, they report the percentage of harvest that is pending which we use to estimate their total output. In the 2013/14 wave, the most common crops in Ethiopia based on the percentage of households who produce it are maize (57 percent), sorghum (43 percent), tea leaves (40 percent), coffee (29 percent), and wheat (25 percent). We restrict our analysis to crops only and hence abstract from livestock as the production cycles of livestock are usually longer than one year, which is our data period. To aggregate farm production of different crops, we use common crop prices. For our purposes, the key is that aggregate production at the farm level reflects physical variation in output. Valuing output at common prices therefore allows us to compare output across farms, reflecting variation in quantities produced. Less important is what common price we use. Since we observe the prices of crops traded at local markets, we compute for each crop the median price among all transactions and use it as the common price of this crop. The value of the crop output of a farm is estimated by multiplying the physical quantity produced with its common price. We then sum up the values of all crop types produced by the farm to obtain the value of gross output of each farm. We also use common prices to estimate the value of intermediate inputs used by farms, such as fertilizers and seeds, in a similar way. Note that some fertilizers and seeds are from the farmers' home production; we evaluate these home-produced goods using common market

prices as well. Again, the key in these assumptions for our purpose is that the aggregate measure of intermediate inputs used on a farm tracks physical variation in inputs as best as possible. We calculate the value added of a farm by subtracting the value of intermediate inputs from the value of gross output. We use this measure of value added in our analysis as the net farm output.

Rain. To measure productivity, it is important to exclude transitory variation in output from value added. In agricultural production, the most important shock is precipitation. 
Rainfall information is provided in the data, recorded as the annual precipitation in millimeters, and we use it to identify shocks in rainfall. We create 10 dummies representing different levels of rainfall. Then, we regress the calculated farm value added on those dummies and obtain the residual of this regression as the value added excluding the transitory variation due to rainfall shocks. This is the measure of farm value added we use in our analysis.

Land. Land input of a farm (i.e., farm size) is the sum of the size of all land plots operated by this farm. In the 2013/14 wave, the size of 93.8 percent of land plots is accurately measured by GPS or, in case of small fields, by compass and rope at a precision of 0.1 square meters, while the size of the remaining land plots is reported by farmers. Farms are in general very small in Ethiopia. In the 2013/14 wave, the average farm size in our sample is around 1.3 hectares, compared to 169.2 hectares in the United States as reported in the 2007 U.S. Census of Agriculture. The farm size distribution is skewed to very small sizes: 64.7 percent of households in our sample operate farms smaller than one hectare, 86 percent of households operate farms smaller than two hectares, and only two percent of households operate farms larger than five hectares. We note that a plot of land is treated as a part of a particular farm if it is operated by that farm, regardless of whoever has the use rights of the land. In other words, the size of the farm is the operational scale and not the ownership or use rights of land. Therefore, when computing farm size, we include rented-in land plots and exclude rented-out plots for each household.

Land quality. The survey also records land quality and other geographical characteristics for each plot of land. For each plot, we have information on its elevation, slope, terrain roughness, nutrient availability, nutrient retention, rooting conditions, excess salts, toxicity, and workability. These observed dimensions capture the most important features of land quality. The issue is how to combine these measures of land characteristics into one aggregate measure of land quality. We regress log value added per labor hour on all these indicators of land quality, controlling for log capital and land input per labor hour. This regression estimates how these dimensions of land quality affect farm value added per labor hour. Then, we take the coefficients from this regression to construct a land quality index $q$ for each farm. This coefficient $q$ summarizes land quality using the best possible observed information in our data. We recognize that there may still be other unobserved dimensions 
of land quality differences among plots, and hence our goal with this approach is to control on land quality differences as much as possible based on the observed information, without asserting conclusions on the specific measure of land quality.

Capital. Farm capital has three components: agricultural tools, transportation tools, and some livestock. Agricultural tools include sickles, axes, pick axes, traditional or modern ploughs, and water pumps. We observe the physical quantity of these tools owned by each farmer, as well as their prices at local markets. Again, we construct common prices, defined as the median of sell prices, to evaluate these agricultural tools. Transportation tools include hand-pushed or animal-drawn carts and bicycles. The price of transportation tools are not directly available in the data, so we estimate their values using local prices from the internet. We assign the prices of transportation tools as follows: one hand-pushed cart is worth about 6 traditional ploughs; one animal-drawn cart is about 9 traditional ploughs; one bicycle is about 17 traditional ploughs. Note that very few farmers have these transportation tools, so excluding them in the measure of capital would only change our results slightly. The livestock used for agricultural crop production are a bit more complicated. The survey records the three most common livestock in Ethiopia, cattle, goats, and sheep, as well as their farm use. In our measure of capital, we only include cattle that are for agricultural or transportation purposes, and exclude goats and sheep, which are mainly used for meat, wool, or milk. We also observe the prices at which farmers sell their cattle. Given this, we construct common cattle prices separately for male and female cattle, to evaluate livestock value. Finally, we sum up the values of agricultural tools, transportation tools, and cattle as our measure of farm capital. To deal with a set of farmers who have zero measured capital but report cultivated land and positive production, we follow Adamopoulos et al. (2017) in imputing an amount of capital to all farms representing a common set of very small tools and structures used by farmers that are not recorded in the data. The amount we assign to each farmer is set to equal ten percent of the median capital-land ratio of farms within the zone, multiplied by the amount of land input of the farm. We have verified that our results are not sensitive to the size of adjusted capital or to dropping these households.

Labor. The data provide labor input for every plot of land of a farm, in both the planting season and the harvest season. Labor input includes farmers' family labor, hired labor, and 
unpaid labor from other households. Family labor is recorded in hours (the data reports hours per day, days per week, and number of weeks per season); hired labor and unpaid labor, however, are only recorded in days. We assume that hired men work the same hours per day as male family members, and hired women and children work the same hours as female and children family members, respectively. Furthermore, we adjust labor hours of women and children as efficiency units of men hours using the median wage ratios relative to men to obtain the male-equivalent hours. We also assume that unpaid labor from other households work the same hours per day as hired workers of the same identity: For example, unpaid men work the same hours per day as hired men, and we apply the same quality adjustment as well. Finally, we construct farm labor input as the sum of hours from all three types of labor for all land plots of this farm in both seasons. We find that, out of total labor input, 75.3 percent is supplied by household members, 14.7 percent by hired labor, and 10.0 percent by unpaid labor from other households.

\section{B Factor Income Shares}

We document our procedure to estimate factor shares using the Ethiopian micro data. Factor shares are calculated as the share of cost of each factor in production. We also discuss robustness of our results with respect to the their values.

Labor share. We observe the wage payments for hired labor, separately for male, female, and children. We then calculate the cost per day for these three types of labor by taking the median wage rate of each type. For household members and free labor from other households, we do not observe the cost. We hence impute the cost by assigning the same wage rate as hired labor of the same type. For example, we assume that using male household members has the same cost as using the same amount of hired male individuals. By doing this, we calculate the labor cost of each farm. We then take the ratio between this labor cost and the farm output (value added), and take the median (0.464) as the labor income share.

Land share. We observe the land payments, both cash and in-kind, for some land rentals. There is a substantial portion of rentals that are non-market, that is involving no payment in cash or in kind. We therefore calculate the land share using the portion of rentals that 
are market, i.e., the payment is not zero. The cost of land is then as the ratio between rental payments and rental size. We take the median of this ratio to be our measure of land price. Then for all land plots, regardless of rented or own, we apply this price to calculate the implied cost of land. We next aggregate this land cost to the farm level to obtain the shadow land cost of each farm, including both rented land and own land. Finally, we calculate the ratio between this implied land cost and the farm output (value added), and take the median (0.389) as the land income share.

Capital. We do not directly observe the capital cost. We therefore use the residual as the capital share, which is $1-0.464-0.389=0.147$.

To summarize, we estimate that capital, labor, and land income shares are $0.147,0.464$, and 0.389 , respectively. Note that estimates of factor income shares in agriculture varies in the literature. Valentinyi and Herrendorf (2008) find that in the United States, capital, labor, and land income shares in agriculture are 0.36, 0.46, and 0.18. Restuccia and SantaeulàliaLlopis (2017) use micro data from Malawi and estimate capital, labor, and land shares to be 0.190, 0.419, and 0.391. The discrepancy among the shares may arise from the fact that the capital income share in agriculture tends to increase as an economy develops (Chen, 2020). Ethiopia is typically considered to be at a stage of development similar to Malawi, and our estimated factor income shares are close to those of Restuccia and Santaeulàlia-Llopis (2017).

A difficulty with estimating factor income shares in poor and developing countries is the fact that only a subset of factor services are transacted in a market for which we observe factor payments. To the extent that there may be selection in the set of observed transactions, factor income shares may be biased. A similar bias may arise if observed transactions are subject to distortions. We recognize the difficulty of dealing with these issues given our current data and to even assign the direction of the bias. To address the importance of factor shares values for our results, we conduct the following robustness checks. First, we use factor income shares from Restuccia and Santaeulàlia-Llopis (2017). These shares are estimated using only capital and land payments, not labor payments, in a larger sample of market transactions for Malawi, and hence, less subject to selection issues on land income. Using these shares we re-estimate farm productivity and find it to be highly correlated with our baseline productivity with the Spearman's rank correlation of 0.99 . We also re-estimate 
Table 6: Robustness on Factor Shares in Production

\begin{tabular}{lcccc}
\hline & $\begin{array}{c}\text { Correlation } \\
\text { with Baseline }\end{array}$ & $\begin{array}{c}\text { Efficiency } \\
\text { Gain }\end{array}$ & MPLa & TFPR \\
\hline Baseline & - & -0.110 & -0.170 & -0.094 \\
Malawi shares & 0.99 & -0.103 & -0.170 & -0.085 \\
& & $(0.064)$ & $(0.064)$ & $(0.066)$ \\
No capital & 0.96 & -0.194 & -0.170 & -0.170 \\
& & $(0.082)$ & $(0.064)$ & $(0.064)$ \\
DRS $=0.7$ & 0.98 & -0.248 & -0.170 & -0.121 \\
& & $(0.123)$ & $(0.064)$ & $(0.062)$ \\
DRS $=0.5$ & 0.99 & -0.090 & -0.170 & -0.087 \\
& & $(0.043)$ & $(0.064)$ & $(0.066)$ \\
\hline
\end{tabular}

Notes: The first column reports the rank correlation of farm productivity in each case with respect to our baseline measure. The remaining columns report the results of regression (8) for the three measures of farmlevel misallocation: (a) efficiency gain, (b) marginal product of land, and (c) revenue productivity, with treatment and control groups for zones with increased and non-increased land certification shares. Standard errors are calculated using block-bootstrap clustering at the zone level and are reported in parentheses. Data for the Ethiopia ISA 2013/14 and 2015/16 waves.

our main empirical specification between certification shares and farm-level misallocation, and obtain coefficients of efficiency gain, MPLa, and TFPR that are close in magnitude to our baseline, see Table 6 .

Second, note that the implicit returns to scale parameter in our farm production function is the sum of the capital and the land shares and our estimate for the decreasing returns parameter is similar to that in Restuccia and Santaeulàlia-Llopis (2017) and Gollin and Udry (2017) using different identification strategies. In this context, we hold the value of the decreasing returns parameter and consider variations in the shares between capital and land. Particularly, we assign zero share to capital which implies a larger role for land than in our baseline. In this case, farm productivity still is highly correlated with our baseline (0.96) and the main empirical results are similar as well, see Table 6. Third, we use alternative values for the returns to scale parameter, a higher value of 0.7 and a lower value of 0.5 relative to our baseline. We re-estimate farm productivity in each case and again find it highly correlated with our baseline (with rank correlation of 0.98 and 0.99 ) and similar significant empirical results (see Table 6). We hence conclude that our main results are robust to reasonable variations in the values of factor shares parameters. 


\section{Robustness and Extensions}

We provide a set of robustness checks and discuss some extensions to our empirical analysis.

\section{C.1 Controlling for Household-Level Observables}

We repeat the difference-in-difference regression assessing our three measures of misallocation, with treatment and control groups defined as zones with increasing and non-increasing certification shares, explicitly controlling for a set of household-level observables such as the household head's age, gender, education, marital status, health status, and the household's size. Note that further controlling for land quality measures, such as elevation or slope, does not change our results since they are already taken into account when removing land quality from farm level measures of output. In addition, we observe in the data the borrowing behavior of farmers. Particularly, we observe whether farmers successfully borrow from external sources, and whether farmers fail in a borrowing activity. We hence also control for these event dummies in the robustness. The coefficients for efficiency gain, MPLa, and TFPR are $-0.114(0.051),-0.181(0.067)$, and -0.102 (0.066), respectively, very similar to those in Table 3. Including household-level observables and collateral constraint indicators as controls does not alter the effects of land rental markets on resource misallocation. Interestingly, we find that larger certification shares are significantly correlated with borrowing events in the cross-sectional data, while this association is insignificant if we assess the changes over time. This may imply a lag from land certification reform to the reactions in borrowing behaviors.

\section{C.2 Output Market Distortions}

Our emphasis has been on connecting misallocation with restrictions to land markets in Ethiopia. However, to the extent that there may be other frictions in the economy that may be driving misallocation, such as poor infrastructure which would make markets in remote rural locations difficult to access, it is relevant to assess the extent of other frictions. To this effect, we exploit the availability of data on farm distance to markets as a proxy for other frictions such as product market distortions and assess the extent to which these variables are related to farm-specific measures of distortions. In particular, we extend our 
benchmark difference-in-difference specification, which identifies the causality between certification shares and misallocation, to include farm distance to nearest market denoted by dist $_{i}$ as an additional control variable. We find that controlling for output market distortions does not alter our benchmark results. The estimated coefficient $\psi$ (and standard errors) for efficiency gains, MPLa, and TFPR barely change, with -0.110 (0.049), -0.170 (0.064), and -0.094 (0.065), respectively. The coefficients on log distance for dependent variables of efficiency gains, MPLa, and TFPR are insignificant with estimates of -0.027 (0.042), -0.020 (0.041), and $-0.044(0.037)$, respectively. These results suggest that the bulk of overall misallocation in Ethiopia occurs within narrow geographical areas, such as a zone in our analysis, that share similar market access.

\section{C.3 Explicit Labor Input}

That the functioning of labor markets in poor countries is far from perfect is well known (Rosenzweig, 1978, 1988; Rosenzweig and Wolpin, 1985; Behrman, 1999). We abstracted from labor input in our analysis because most farm labor is family labor and hence have avoided the notion of splitting families in reallocation. We show that our results are robust to explicitly including labor in the production function. Recall that in our benchmark production function output $\left(y_{i}\right)$ and inputs $\left(k_{i}, l_{i}\right)$ are all normalized by labor input. Alternatively, we consider an expanded production function where we explicitly include the labor input:

$$
y_{i}=s_{i}^{1-\gamma}\left(k_{i}^{\alpha} n_{i}^{\theta} l_{i}^{1-\alpha-\theta}\right)^{\gamma}
$$

where $n_{i}$ is labor input and $\theta \gamma$ is the corresponding factor share. In this case, the farm productivity can be calculated as $s_{i}=\left[\frac{y_{i}}{\left(k_{i}^{\alpha} n_{i}^{\theta} l_{i}^{1-\alpha-\theta}\right)^{\gamma}}\right]^{\frac{1}{1-\gamma}}$, and the efficient allocation requires $k_{i}^{e}=$ $\frac{s_{i}}{\sum_{i} s_{i}} K, \quad n_{i}^{e}=\frac{s_{i}}{\sum_{i} s_{i}} N, \quad l_{i}^{e}=\frac{s_{i}}{\sum_{i} s_{i}} L$, where $N=\sum_{i} n_{i}$ denotes the aggregate labor endowment. The efficient aggregate output per zone is $Y^{e}=\sum_{i} y_{i}^{e}=\left(\sum_{i} s_{i}\right)^{1-\gamma}\left(K^{\alpha} N^{\theta} L^{1-\alpha-\theta}\right)^{\gamma}$. Analogously, farm revenue productivity (TFPR) is now defined as $\mathrm{TFPR}_{i} \equiv \frac{y_{i}}{k_{i}^{\alpha} n_{i}^{\theta} l_{i}^{1-\alpha-\theta}}$.

In this alternative specification, we have three parameters to calibrate: $\gamma, \alpha, \theta$. Note that the labor income share is now given by $1-\gamma+\theta \gamma$, where $1-\gamma$ is the profit of the farm and $\theta \gamma$ is the share of labor input. We therefore set $1-\gamma+\theta \gamma=0.464$ to match the labor 
share of 0.464 as in our benchmark specification. Recall that family labor accounts for 75.3 percent of total farm labor. We then choose the first component $1-\gamma$ to be 75.3 percent of the total labor share, which means $\gamma=0.651$. The capital share, $\alpha \gamma$ is 0.147 , and hence we choose $\alpha=0.202$.

We re-estimate our benchmark difference-in-difference specification, which identifies the causality between certification shares and misallocation, with this modified setup. We find that our results remain qualitatively similar although the magnitudes are a bit smaller: The estimated coefficient $\psi$ (and standard errors) for efficiency gains, MPLa, and TFPR are $-0.051(0.049),-0.140(0.080)$, and $-0.074(0.051)$, respectively. Notice that in this modified setup, we reallocate factor inputs (including labor) within zones. That is, we are not allowing for reallocation gains potentially generated from (internal) migration which we think deserves further exploration. For such analysis in different contexts, see Munshi and Rosenzweig (2016) for India and Bryan and Morten (2019) for Indonesia. For a cross-country analysis, see Hendricks and Schoellman (2018).

\section{Additional Empirical Results}

In addition to our main empirical results that higher certification shares facilitate rentals and reduce resource misallocation, we also use our data to explore more specific aspects of this relationship. Particularly, we assess the non-linear effects of land rentals on misallocation, and effects of the land certification reform on formal versus informal rentals. We also compare zones with mature versus emerging certification shares.

Non-linear relationship. Our results capture how land rentals relate to farm-level mea-

sures of misallocation on average. However, our theoretical framework implies that efficiency gains are larger when resources are reallocated among farmers with the larger deviations from efficient production. As a result, it is relevant to assess whether rental markets empirically ease misallocation disproportionally more for farmers farthest away from efficient production. To explore the potential non-linear relationship between land markets and misallocation across farmers, we divide the distribution of our measure of misallocation in the base year, $m_{i z}$, into four quantile groups (quartiles) and run the following regression separately for each 
Table 7: Non-Linear Relationship between Land Rentals and Misallocation

\begin{tabular}{lccc}
\hline \multirow{2}{*}{ Dependent variable: } & \multicolumn{3}{c}{ Farm-Level Misallocation } \\
& Efficiency Gain & MPLa & TFPR \\
\hline$\psi_{Q 1}$ & -0.029 & -0.104 & -0.007 \\
& $(0.043)$ & $(0.063)$ & $(0.066)$ \\
$\psi_{Q 2}$ & -0.051 & -0.053 & -0.093 \\
& $(0.044)$ & $(0.056)$ & $(0.056)$ \\
$\psi_{Q 3}$ & -0.150 & -0.085 & -0.087 \\
& $(0.047)$ & $(0.047)$ & $(0.052)$ \\
$\psi_{Q 4}$ & -0.285 & -0.390 & -0.346 \\
& $(0.106)$ & $(0.139)$ & $(0.136)$ \\
\hline
\end{tabular}

Notes: Results of regression (14) for the following measures of farm-level misallocation: (1) efficiency gain, (2) marginal product of land, (3) revenue productivity. Standard errors are calculated using block-bootstrap clustering at the zone level and are reported in parentheses. Data from Ethiopia ISA 2013/14 and 2015/16 waves.

group:

$$
m_{i z t}=\alpha_{Q z}+\lambda_{Q t}+\psi_{Q} d_{z t}+\beta_{Q} \log \mathrm{TFP}_{i z}+\varepsilon_{i z t}
$$

where the first quantile $(Q 1)$ represents farms that are closest to their efficient operational scale, and the last quantile $(Q 4)$ consists of farms that are farthest from their efficient operational scale. In this quantile specification, we compare groups defined within each quantile. For instance, for Q4, we compare the farmers farthest from efficiency in zones where rentals increase to those who are also farthest from efficiency in zones whose rentals do not increase. Our findings are reported in Table 7. The relationship between land rentals and misallocation is nonlinear, consistent with the theoretical framework. Specifically, land rentals are not associated with much changes in efficiency gains for farmers that are already close to their efficient allocation. The negative relationship between land rentals and efficiency gains starts to be significant in the third quantile, with $\psi_{Q 3}=-0.150$, and substantially increases as we move away from efficiency with significant elasticities of $\psi_{Q 4}=$ -0.285 in the fourth quantile. The results are similar with other farm-level measures of misallocation, MPLa and TFPR, see the last two columns of Table 7.

Formal and informal land rentals. Land markets in economies with rich histories of tensions in land arrangements such as Ethiopia may not effectively direct resources to best uses. A nice feature of our dataset is that it provides information about whom the land 
is rented from. Using this information we find that among the households that rent in land the vast majority rent land from relatives (46 percent) and friends (36 percent). This suggests that land reallocations may obey other goals such as redistribution or the provision of social insurance (Kinnan and Townsend, 2012; Munshi and Rosenzweig, 2016). ${ }^{8}$ Since land rentals from relatives and friends are not necessarily ineffective, we instead use the available information on land rental payment arrangements agreed before cultivation between the renter and the rentier to attribute a land rental as either formal or informal. In particular, if a rental contract specifies a plot to be rented for free, then it is likely that this land rental is not market-based and that other considerations are at play. Following this idea, we define informal land rentals as those that are stipulated to be for free (zero rental payments) in the rental contract and formal rentals as those for which the rental contract stipulates a non-zero rental payment. Extending the definition of informal rentals as those with small nominal payments agreed in the rental contract delivers similar results. Notice that our definition of formal rentals - which adds stipulated payments in cash and in kind - includes sharecropping contracts (Shaban, 1987; Sadoulet et al., 1997; Burchardi et al., 2018) as long as the ex-ante agreed amount of shared crops between the renter and the rentier is nonzero. We then estimate Equation (9) separately for formal and informal rental shares. We find that the land certification reform mainly promotes formal rentals, with coefficient (standard error) of $0.046(0.018)$. On the contrary, we find that land certification reform has little effect on informal rentals. The coefficient (standard error) is 0.008 (0.019). This comparison hence indicates that land certification mainly promotes formal rentals. Intuitively, land certification reform may reduce the cost of rentals and/or improve law enforcement on land disputes, and hence renting formally to market may become more attractive compared to renting to families and friends informally.

Maturity of land markets. We also assess the relevance of the maturity of land markets. To do so, we also compare zones with substantial and established land certifications (zones where land certification shares are consistently above 70\% in both 2013/14 and 2015/16) with zones featuring emerging land certifications (zones where rentals increase but not con-

\footnotetext{
${ }^{8}$ See also Rosenzweig and Stark (1989), Townsend (1994); Udry (1994), De Magalhães and SantaeulàliaLlopis (2018), Morten (2019), and Kinnan (2019).
} 
sistently above 70\%). This implies that we have two control groups: a control group where the reform is not implemented and a control group where the reform has been largely finished. The second control group comprises approximately a quarter of our original sample of households. We then apply the estimator of Goodman-Bacon (2019) to our difference-indifference specification and find that our results remain largely unchanged. The coefficients (standard errors) for land rental shares, efficiency gain, MPLa, and TFPR are 0.051 (0.023), $-0.126(0.023),-0.178(0.025)$, and -0.102 (0.023). These results are similar to our baseline specification and indicate that compared to mature zones where land certification reform is more advanced, emerging zones more substantially increase rentals and reduce misallocation. 